УДК 811.11

И. Э. Федюнина

\title{
ФРАЗЕОЛОГИЧЕСКИЕ НОМИНАЦИИ ДЕНЕГ В РУССКОМ И АНГЛИЙСКОМ ЯЗЫКАХ
}

Федюнина I. Е. Фразеологічні номінації грошей у російській та англійській мовах.

У статті розкрито і проаналізовано семантичні моделі фразеологізмів російської й англійської мов із загальним значенням «Гроші». Фразеологізми розглянуто як засіб створення прагматичного ефекту й виявлення специфіки оціночного сприймання феномену грошей носіями досліджуваних мов.

Ключові слова: фразеологізм, фразеосемантична модель, гроші, прагматичний ефект, флуктуація, дискурсивне функціонування.

Федюнина И. Э. Фразеологические номинации денег в русском и английском языках.

В статье выявляются и анализируются семантические модели фразеологизмов русского и английского языков с общим значением «Деньги». Фразеологизмы рассматриваются как средство создания прагматического эффекта и выявления специфики оценочного восприятия феномена денег носителями исследуемых языков.

Ключевые слова: фразеологизм, фразеосемантическая модель, деньги, прагматический эффект, флуктуация, дискурсивное функционирование.

Fedyunina I. E. Russian and English idioms used for describing money.

The article focuses on analysing Russian and English idioms with general meaning of money. Idioms are examined as a means of creating pragmatic impact and revealing the attitude of Russian and English native speakers to phenomenon of money.

Key words: idiom, phraseosemantic model, money, pragmatic impact, fluctuation, discourse functioning.

Статья посвящена исследованию особенностей семантики и контекстуального функционирования фразеологических единиц (ФЕ), объективирующих представления носителей русского и английского языков (РЯ и АЯ) о финансовых доходах.

Сегодня общепризнан огромный потенциал ФЕ как единиц, обладающих «повышенной познавательной ценностью» [3, с. 31]. Поскольку «языковое воздействие может быть... и понятийным и эмоциональным», а «экспрессивная семантика языковых единиц является... коммуникативно значимой» [6, с. 137], наиболее ценным для когнитивных исследований свойством ФЕ представляется их способность к характеризующей номинации, то есть называнию и одновременно оценочной характеристике объекта. Специалисты, исследовавшие прагматические возможности языковых (в том числе фразеологических) единиц $[1 ; 2 ; 3 ; 4 ; 5 ; 9]$, убеждены в том, что ключевыми характеристиками ФЕ, обеспечивающими их прагматическое воздействие на реципиента, являются образность, богатый импликационал и специфика оценочного компонента значения, которая 
проявляется в конкретном дискурсе. Понимание дискурса как «сплава языковой формы, знаний и коммуникативно-прагматической ситуации» [1, с. 450] подразумевает его ключевую значимость как фактора создания и трансформаций прагматического эффекта ФЕ. Именно в дискурсивном функционировании ФЕ реализуются специфические или дополнительные смыслы, которые несут эти языковые единицы наряду с общим значением. Кроме того, специфическим свойством семантики некоторых ФЕ является способность их оценочного компонента к флуктуации при попадании ФЕ в контекст. Это свойство особенно характерно для ФЕ, объективирующих феномены действительности, к которым носители языка испытывают неоднозначное, противоречивое отношение.

К числу таких феноменов безусловно относятся деньги, являющиеся в современном обществе не только средством к существованию, но и материальным воплощением статуса, степени успешности, а зачастую также мерилом (показателем) способности человека к профессиональной и личностной самореализации и достижению поставленных целей. Однако в психологическом плане восприятие денег неоднозначно. С одной стороны, получение прибыли, наряду с удовлетворением от победы и успеха, является главной целью любой профессионально-деловой активности, а устремлённость к получению денег как источнику различных благ и удобств - неотъемлемым свойством человеческой природы. С другой стороны, стремление к максимально возможной финансовой прибыли нередко стимулирует развитие таких малопривлекательных качеств субъекта как агрессивность, алчность, неразборчивость в средствах и т. д. Кроме того, далеко не все члены общества разделяют общепринятые представления о роли и значимости денег. Поэтому оценочное восприятие денег, равно как и способов их получения и употребления, неоднозначно и зачастую носит ситуативно-субъективный характер.

Поскольку анализ контекстуального функционирования ФЕ помогает раскрыть «различные аспекты внутреннего мира языковой личности» [1, с. 451], можно предположить, что сопоставительное изучение ФЕ, характеризующих деньги, позволит выявить особенности представлений носителей исследуемых языков о данном феномене.

При анализе фразеологических характеристик финансовых доходов мы условно выделили несколько фразеосемантических моделей, актуализирующих количество, происхождение, способы добывания и употребления денег. Здесь будут рассмотрены три из них.

Первая модель (группа) представлена ФЕ с общим значением «много денег»- денег куры не клюют, денег хоть жсги, топеу to burn и др. На первый взгляд, ФЕ, репрезентирующие финансовое изобилие, должны иметь однозначно позитивную коннотацию. Однако в большинстве контекстов эти ФЕ проявляют флуктуацию оценки. Вероятно, это во многом обусловлено двойственностью их внутренней формы, которая, несмотря на частные 
лексические расхождения, даёт сходные по сущности образы в обоих языках: с одной стороны чётко актуализируется образ изобилия, с другой - признаки излишества и, как следствие, импликация некоторой неестественности, а также неспособности обладателя таких денег найти им адекватное применение. Контексты также демонстрируют неоднозначность восприятия большого количества денег. Наряду с указанием на материальную обеспеченность и комфортную жизнь субъекта часто актуализируется потенциальная опасность того или иного рода, подозрительное отношение к источнику доходов, а также перспектива стать объектом махинаций или циничного использования: ...какого-то влюблённого племянника изображает. И боюсь, что только ради денег. А их у неё... куры не клюют [2, с. 357]; Итак, на Россию пролился золотой дождь западных инвестиций. Приятно, конечно, когда «с неба» падают деньги, но вот вопрос: как будем отдавать? [2, c. 347]; He seems to have money to burn - I wonder where he gets it all from $[11$, c. 258]. Кроме того, обладатели больших денег, как правило, не пользуются благожелательным отношением окружающих. В РЯ нередко объективируется желание воспользоваться имеющимися у субъекта «излишками» или вовсе их отобрать. При этом потенциальный грабитель зачастую не испытывает угрызений совести; напротив, факт наличия у другого человека большого количества денег воспринимается им как некая несправедливость, которую необходимо исправить: Э, да у вас, гражданин, червонцев-то куры не клюют. Поделился бы, a? [2, с. 346]. В АЯ откровенно неприязненное отношение обнаруживается нечасто. Хотя во многих контекстах эксплицируется наличие у богатых людей возможностей, которых нет у остальных, эта экспликация носит скорее характер констатации факта и не вовлекает эмоционально-нравственных оценок: The only people who can afford to stay at this hotel are rich people with money to burn [8, c. 258].

Вторую фразеосемантическую группу составляют ФЕ easy money, money for old rope, money for jam, a fast buck, лёгкие деньги, быстрые деньги, длинный рубль и т.д., обозначающие деньги, добытые быстро и без особых усилий. Все они имеют флуктуирующую оценку и проявляют достаточно высокую степень дискурсивной зависимости. Однако оттенки восприятия доходов, репрезентируемых данной группой ФЕ, и признаки, выделяемые как наиболее существенные при оценке действий субъекта, разнятся у носителей исследуемых языков.

Рассмотрим три характерных примера АЯ. 1) It was money for old rope. All we had to do was to sing a couple of songs; in return we got a free lunch and $\$ 14$ [10, c. 233]; Tom is always ready to make a fast buck [10, c. 421]; 2) Modelling is easy money, but it doesn't last long [10, c. 232]; 3) The difficulty of tracing musical gear makes it easy money for thieves [10, c. 232]; ...most property here... is now owned by vast companies who don't care about the town and people, just the fast buck [8, с. 130]. Анализ приведённых ситуаций () И. Э. Федюнина, 2013. 
позволяет выделить три аспекта восприятия лёгкого и быстрого заработка носителями АЯ. Первый из них носит позитивный рационально-практический характер - получение дохода не требует больших усилий, а выгода часто превышает вложенный труд. Также эксплицируется готовность взяться за всякую работу, сулящую подобный заработок. Второй пример показывает недолговечность и ненадёжность таких доходов, что придаёт ФЕ пренебрежительную коннотацию. В третьем случае объективируются ситуации, в которых ради получения прибыли совершаются поступки не только противозаконные, но и безнравственные. Здесь коннотация ФЕ меняется на негативную, причём вовлекаются и практический и эмоционально-нравственный аспекты оценки - акцентируется как финансовый ущерб, наносимый реципиенту в результате мошенничества, так и неразборчивость субъекта в средствах и полное безразличие к людям, которые пострадают от его действий.

Перейдём к анализу контекстов РЯ: 1) ...mpи дня «зарабатьввал на стороне», чтобы понять, как можно сегодня в Москве законно «поднять» лёгких денег. Итог... получился до банальности простыл: за ничегонедалание никто платить не будет, это бывает только в сказках [2, с. 338]; 2) Вокруг Кати кичели посредники, ворьё - все хотели делать деньги из воздуха. Катя погружсалась в стрессыл... [7, с. 281]; 3) Учитыввая повальный людской интерес клёгким деньгам, да ещё и быстрым к тому же..., поделюсь опытом. Обратите внимание... на современных маньяков-потребителейлюди в считанные минуты и даже секунды расстаются с деньгами, за которые паиут месяцами... Ну и разве это не лёгкие деньги - продать людям что-то, что вообще денег не стоит, но им кажется стоящей вещьюю... Заплатят и ещё будут счастливы, пусть это и счастье идиота... [2, с. 338]. В целом в оценочном восприятии носителей РЯ наиболее характерными видятся следующие тенденции. Во-первых, акцентируется тотальный характер стремления к получению дохода без особых затрат труда. Такое стремление вызывает довольно разнообразную реакцию как в эмоциональном, так и в практическом аспекте, в зависимости от ситуации и позиции говорящего от резкого неодобрения и осуждения (негативные модификаторы ворьё, cmpeccb, ничегонеделание) до насмешливо-ироничной констатации факта. Также часто актуализируется готовность воспользоваться глупостью и жадностью любителей лёгкого быстрого дохода, к которым говорящий не испытывает ничего кроме презрения (маньяки-потребители, счастье идиота). Во-вторых, лёгкий и быстрый заработок представлен как нечто вообще не существующее в действительности, а попытки его добиться - как пустая трата времени и бессмысленное занятие, чреватое к тому же опасностью.

Третья фразеосемантическая группа характеризует деньги, добытые нечестным путём или используемые в неблаговидных целях (hush money, funny money, dirty monеу, грязные деньги, дурные деньги, иальныле деньги и др.) В рамках этой группы особый интерес представляют культурно-специфичные 
ФЕ, которые объективируют «разновидности» денег, не нашедшие фразеологической репрезентации в других языках. В АЯ яркими примерами таких ФЕ являются hush топеу (плата / взятка за молчание) и funny топеу (деньги, добытые нечестныл путем, фальшивые купюры). Разумеется, отсутствие русскоязычных эквивалентов в данном случае не означает, что подобные способы добывания и применения денег отсутствуют в жизни носителей РЯ - речь идёт лишь о том, что они не получили специфической актуализации на фразеологическом уровне. Рассмотрим несколько контекстов их употребления.

ФЕ hush money в целом имеет отрицательный заряд, что во многом обусловлено компонентом hush, который несёт сему тишины, замалчивания и тем самым имплицирует потенциальную опасность. Однако анализ дискурсивного функционирования данной ФЕ обнаруживает флуктуацию оценки и актуализацию множества дополнительных смыслов. Рассмотрим два примера: His assistant had been paid hush money to stop him from speaking to the press [11, c. 76]; The politician was arrested for trying to pay hush money to a victim of the scandal [10, c. 230]. В приведённых контекстах практический аспект ситуации в целом сходен (собственно, он и репрезентирован денотативным компонентом значения - субъект платит другому человеку деньги за то, чтобы тот не разглашал информацию, которая может привести к негативным последствиям). Однако эмоциональная оценка (и, как следствие, коннотация $Ф Е)$ различна. В первом случае не совсем ясно, какого рода информация замалчивается. Зато лексема press показывает, что разглашение может привести к нездоровому интересу со стороны журналистов и скандалу, которого человек, возможно, не заслужил. Поэтому ФЕ не имеет резко отрицательной оценки. Во второй же ситуации очевидно, что деньги служили субъекту для попытки откупиться от пострадавшего по его вине человека (модификатор victim) и избежать ответственности. В таком контексте негативная коннотация ФЕ не затушёвывается, а, напротив, усиливается. Актуализируются чувства негодования, неодобрения и идея справедливого наказания.

ФЕ funny money несёт фиксированную отрицательную оценку. Прагматический эффект ФЕ funny топеу основан на двойном значении значения лексемы fuпnу (прямое - смешной, забавный, переосмысленное нечестный, преступныцй, фальшивый). Таким образом, компонент fиппу в его переосмысленном значении ассоциируется с опасной игрой, незаконными действиями, что имплицирует необходимость и неизбежность разоблачения и наказания: He was caught passing funny money through the business [11, c. 76]; The bank spotted the funny money in his deposit almost immediately [10, с. 157]. Прагматический эффект ФЕ в приведённых ситуациях усиливается за счёт лексем caught, spotted (обнаружить, поймать). Вместе с тем большинство контекстов практически не обнаруживают эмоциональнонравственных оценок действий субъекта. Акцентируется в основном ๑ И. Э. Федюнина, 2013. 
практический аспект - разоблачение мошенничества и необходимость изъятия фальшивых денег, представляющих опасность для экономики государства.

Теперь обратим внимание на небольшую фразеосемантическую группу безэквивалентных ФЕ РЯ - дурные / мальные деньги и сумасшедшие / бешеные деньги. Здесь особый интерес представляет отношение к деньгам, имплицируемое первым компонентом ФЕ. Они различны по оттенкам значения. Первая пара ФЕ характеризует способ получения и «нравственный» аспект («деньги, полученные не честным трудом, а благодаря случаю, удаче, часто преступным путем»); вторая - «количественный» аспект («очень большие деньги»). Однако в компонентном составе всех четырёх ФЕ очевидны одинаковые семантические признаки-интенсивы, которые можно определить как «отклонение от нормы, несоразмерность, безумие, агрессия»; они, в свою очередь, вызывают ассоциацию с опасностью и отношение презрения, отторжения. Вместе с тем прослеживается ассоциативная корреляция с богатством и удачей, что сообщает таким деньгам своеобразную притягательность. Специфика этих ФЕ заключается в их повышенной экспрессивности и эмотивности. Проследим, каким образом указанные противоречия отражаются в дискурсе: «Спасибо. Mbl бы пропали без тебя». - «Да не за что», смутился Костя, - «я же их не заработал. Шальные деньги, неизвестного происхождения. Может, от наркобизнеса» [7, с. 317]; Скорее всего это деньги, полученные от фальиивой водки или от наркотиков. Иначе откуда такие бешеные суммы у таких молодых людей? [7, с. 317]; Ему подсознательно и сознательно хотелось освободиться от дурных денег. Поменять деньги на результат [7, с. 319]. В приведённых ситуациях актуализируются следующие тенденции восприятия подобных доходов. Источник денег, даже если он достоверно не известен, всегда характеризуется негативно (мысль о том, что они могут иметь «приличное», приемлемое с моральной позиции происхождение, практически не допускается); чётко актуализируются опасение, неодобрение, часто брезгливость, подчёркивается разлагающее воздействие таких доходов. Кроме того, у самого обладателя подобных денег они зачастую вызывают пренебрежение, не имеют для него ни ценности, ни значимости, так как в их добывание не вложен настоящий честный труд. Как следствие, у субъекта возникает настойчивое желание поскорее избавиться от денег, и в конечном итоге способ их употребления зачастую оказывается ничуть не лучше способа получения, как в моральном, так и в практическом плане. Однако необходимо отметить, что многие контексты наряду с негативными оценками обнаруживают сильное желание говорящего самому получать подобные деньги и зависть к тем, кто знает способы / источники их получения.

Кратко рассмотрим ещё одну культурно-специфическую ФЕ РЯ кровныле деньги (деньги, заработанные тяжёлым, зачастую долгим трудом, с максимальным приложением физических, умственных и моральных усилий), в денотативном и оценочном аспектах противопоставляемую ФЕ, 
проанализированным выше. Сама внутренняя форма данной ФЕ обеспечивает ассоциации с кровью как воплощением жизненной энергии и больших жертв, принесённых в процессе добывания таких денег. Kровные деньги воспринимаются уважительно, видятся заслуженной наградой, добытой, возможно, дорогой ценой, и поэтому любая попытка покушения на них вызывает осуждение, возмущение, гнев и т. п.: Сама вероятность использования мошенниками гипноза пугает. В одной из фирм «спецыљ манипулировали чужим сознанием, чтобы выманить у сограждан их кровные деньги [2, с. 338]. Негативную реакцию встречает также небрежное, легкомысленное обращение с кровными деньгами. В подобных ситуациях субъект вызывает презрение, неприязнь: Пока мы будем соглашаться... слушать скрипучих чмочников и трескать рекламируемые отбросы, наши кровные деньги будут идти не в дело, а сами знаете куда [2, с. 338]. Интересно отметить, что происхождение таких денег, даже если они были получены незаконным, преступным путём, часто отодвигается на второй план или вообще затушёвывается - при оценочном восприятии практически всегда доминирует позитивный, вызывающий безусловное уважение признак полной самоотдачи, обеспечивающий как минимум признание права субъекта на владение деньгами и пользование теми благами, которые они дают.

В целом исследование фразеологических номинаций денег позволяет сделать следующие выводы. Денотативный компонент ФЕ, характеризующих деньги, очень богат и позволяет объективировать происхождение, способы добывания и употребления денег, а также отношение к ним. В этом плане можно условно выделить: крупные суммы денег; деньги, добытые нечестным, преступным путём; деньги, добытые быстро и без особого труда; деньги, используемые для сокрытия информации. Оценочное восприятие финансовой прибыли носителями исследуемых языков зависит от того, как она были получена, надёжен ли её источник, наносит ли её получение и использование вред другим людям и т. д. Большинство ФЕ исследуемых языков имеют прозрачную внутреннюю форму, флуктуирующую оценку и обнаруживают достаточно высокую степень дискурсивной зависимости. Именно эти свойства являются ведущими факторами, влияющими на прагматический эффект ФЕ, и позволяют эксплицировать специфику отношения к деньгам и их обладателю при анализе дискурсивного функционирования ФЕ. К общим чертам восприятия финансовой прибыли носителями РЯ и АЯ относятся разнообразные и противоречивые оценки лёгких и быстрых доходов, а также однозначно отрицательное отношение к неразборчивости в средствах, цинизму и жестокости, проявляемых субъектом при добывании денег. Национально-культурная специфика фразеологических репрезентаций и оценочного восприятия денег обнаруживается в следующем: 1) в обоих языках имеются безэквивалентные ФЕ, объективирующие определённые виды доходов и пути их применения; 2) многие ФЕ РЯ обладают большей эмотивностью и 
экспрессивностью, чем ФЕ АЯ; 3) для носителей АЯ характерна тенденция к разделению рационально-практической и эмоционально-нравственной оценки получаемых доходов независимо от их источника, а также меньшая, чем у носителей РЯ, склонность оценивать обладателя денег и его поведение с позиций морали. Дальнейшее сопоставительное изучение ФЕ с семантикой финансового состояния человека представляется ценным и перспективным с позиций как лингвистики, так и межкультурной коммуникации.

\section{Литература}

1. Алефиренко Н.Ф. Культурно-познавательное пространство русской идиоматики : фразеологический словарь / Н. Ф. Алефиренко, Л. Г. Золотых. - М. : ООО «ЭЛПИС», 2008. - 472 с.

2. Большой фразеологический словарь русского языка. Значение. Употребление. Культурологический комментарий / Отв. ред. В. Н. Телия. - [2-е изд., стер.]. - М. : АСТ-ПРЕСС КНИГА. - 784 с.

3. Жуков В. П. Русская фразеология : [учеб. пособие] / В. П. Жуков, А. В. Жуков. М. : Высшая школа, 2006. - 408 с.

4. Мизин К. И. Компаративна фразеология : [монография] / К. И. Мизин. Кременчуг : ПП Щербатих О. В., 2007. - 168 с.

5. Приходько Г. І. Способи вираження оцінки в сучасній англійській мові : [монографія] / Г. І. Приходько. - Запоріжжя : ЗДУ, 2001. - 362 с.

6. Шаховский В. И. Лингвистическая теория эмоций: [монография] / В. И. Шаховский. - М. : Гнозис, 2008. - 416 с.

7. Токарева В. С. Птица счастья : [повести] / В. С. Токарева. - М. : АСТ : ЛЮКС, 2005. -349 c.

8. Cambridge International Dictionary of Idioms. - Cambridge : Cambridge University Press, 1998. - 587 p.

9. Forrester M. A. Psychology of Language. A Critical Introduction / M. A. Forrester. London: SAGE Publications, 1996. - 113 p.

10. Longman Idioms Dictionary : over 6000 Idioms. - London : Pearson Education Limited, 1998. - 398 p.

11. McCarthy M., O’Dell F. English Idioms in Use / M. McCarthy, F.O'Dell. Cambridge: Cambridge University Press, 2010. - 190 p. 